\title{
Methylation of miR-34a, miR-34b/c, miR-124-1 and miR-203 in Ph-negative myeloproliferative neoplasms
}

\author{
Chor Sang Chim ${ }^{1 *}$, Thomas S Wan², Kwan Yeung Wong ${ }^{1}$, Tsz Kin Fung ${ }^{1}$, Hans G Drexler ${ }^{3}$ and Kit Fai Wong ${ }^{4}$
}

\begin{abstract}
Background: MicroRNA (miR) miR-34a, -34b/c,-124-1 and -203 are tumor suppressor miRs implicated in carcinogenesis.

Methods: We studied DNA methylation of these miRs in Philadelphia-negative (Ph-ve) myeloproliferative neoplasms (MPNs). Methylation-specific PCR (MSP), verified by direct sequencing of the methylated MSP products, was performed in cell lines, normal controls and diagnostic marrow samples of patients with MPNs.

Results: Methylation of these miRs was absent in the normal controls. miR-34b/c were homozygously methylated in HEL cells but heterozygously in MEG-01. In HEL cells, homozygous miR-34b/c methylation was associated with miR silencing, and 5-aza-2'-deoxycytidine treatment led to re-expression of both miR-34b and miR-34c, consistent with that both miRs are under the regulation of the same promoter CpG island. miR-34a was heterozygously methylated in MEG-01 and K-562. miR-203 was completely unmethylated in K-562 and SET-2 but no MSP amplification was found in both HEL and MEG-01, suggestive of miR deletion. In primary samples, four each had miR-34b/c and -203 methylation, in which two had concomitant methylation of miR-34b/c and -203. miR-34a was methylated in one patient and none had methylation of miR-124-1. Seven patients (15.6\%) had methylation of at least one of the four miRs. miR methylation did not correlate with clinical parameters, disease complications or JAK2 V617F mutation.
\end{abstract}

Conclusion: This is the first report of miR hypermethylation in MPNs. miR-203 hypermethylation is not specific to $\mathrm{Ph}+\mathrm{ve}$ leukemias but also present in Ph-ve MPNs. miR-34b/c methylation was associated with reversible miR silencing. There was no correlation of miR methylation with clinical demographic data or outcome.

Keywords: microRNA, tumor suppressor, hypermethylation, Ph-negative myeloproliferative neoplasm

\section{Background}

Philadelphia-negative ( $\mathrm{Ph}-\mathrm{ve}$ ) myeloproliferative neoplasm (MPN) is a stem cell disease with proliferation of myeloid lineage, leading to the development of distinct clinical entities including polycythemia vera (PV), essential thrombocythemia (ET) and primary myelofibrosis (PMF) [1-3]. JAK2 V617F mutation, resulting in constitutive activation of JAK-STAT signaling, occurs in about half of the patients with ET and PMF but in more than $90 \%$ of patients with PV [1].

\footnotetext{
* Correspondence: jcschim@hku.hk

'Department of Medicine, Queen Mary Hospital, The University of Hong Kong, Hong Kong

Full list of author information is available at the end of the article
}

Gene methylation is an alternative mechanism of gene inactivation, and various tumor suppressor genes regulating the cell cycle, apoptosis and cell signaling have been shown to be hypermethylated in hematological malignancies [4].

MicroRNA (miR) is a single-stranded, non-coding RNA molecule of 22-25 nucleotides, which leads to downregulation of target protein expression [5]. miRs are involved in carcinogenesis [6]. miRs can be either oncogenic (oncomir) when tumor suppressor genes (TSG) are targeted, or tumor suppressive (tumor suppressor miRs) when oncogenes are targeted [7].

Recently, $m i R-34 a$, $m i R-34 b / c$, $m i R-124-1$ and $m i R-203$ hypermethylation have been implicated in carcinogenesis.

\section{Ciomed Central}


Hypermethylation of $m i R-34 a$, a transcriptional target of p53, has been demonstrated in solid and hematopoietic cancers $[8,9]$, whereas restoration of which will inhibit CDK6 translation by complementary binding to the 3' untranslated region (3' UTR) of the CDK6 mRNA and induce apoptosis, thereby showing the tumor suppressor role of $m i R-34 a$ [8]. Epigenetic inactivation of $m i R-34 b$, another p53 downstream target of the miR-34 family, has also been implicated in acute myeloid leukemia (AML), and the re-expression of $m i R-34 b$ led to suppression of CREB expression and inhibition of cell proliferation [10]. Promoter methylation of miR-124-1, the first tumor suppressor miR found to be regulated by DNA methylation, has been shown to confer poor prognosis of acute lymphoblastic leukemia (ALL) [11]. Moreover, hypermethylation of $m i R-203$ has been reported in chronic myeloid leukemia (CML), conferring a proliferative advantage to the tumor cells by inhibiting the oncogenic BCR-ABL fusion protein [12]. In Ph-ve MPN, little is known about the epigenetic alteration of miR methylation. In this report, we studied the methylation status of $m i R-34 a$, $m i R-34 b / c, m i R-124-1$ and $m i R-203$ in PV, ET and PMF.

\section{Methods}

\section{Patient samples}

DNA was extracted from primary marrow samples at diagnosis of 45 patients with MPN [ET, N = 34 (75.5\%); PV, $\mathrm{N}=8(17.8 \%)$ and PMF, $\mathrm{N}=3(6.7 \%)]$. There were $24(53.3 \%)$ male and $21(46.7 \%)$ female patients with a median age of 67.5 years (range: 28 - 89 years), a median presenting platelet count of $848 \times 10^{9} / \mathrm{L}$ (range: 196 $\left.2275 \times 10^{9} / \mathrm{L}\right)$, a median presenting hemoglobin level $(\mathrm{Hb})$ $13.3 \mathrm{~g} / \mathrm{dL}$ (range: $9-22 \mathrm{~g} / \mathrm{dL}$ ), and a median presenting leukocyte count of $14.4 \times 10^{9} / \mathrm{L}$ (range: 7-28 $\times 10^{9} / \mathrm{L}$ ). Apart from five (11.1\%) patients in whom the presenting symptomatology at presentation were not available for review, 25 (62.5\%) were asymptomatic at diagnosis, four (10\%) with bleeding, four (10\%) with erythromelalgia, two (5\%) with minor stroke, three (7.5\%) with abdominal pain, and one each (2.5\%) with blurred vision and weight loss. Of 39 patients with adequate follow-up information, five (12.8\%) had myeloid transformations (MDS or AML) at the time of study. Of 40 patients with data on thrombosis, nine (22.5\%) had thrombotic events. Apart from 5 patients with unknown JAK2 mutation status, 26 (65\%) had JAK2 V617F mutation. (Table 1) The study has been approved by Institutional Review Board of Queen Mary Hospital with written informed consent.

\section{Cell lines and culture}

MEG-01 and K-562 cells were kindly provided by Dr Mo Yang, Department of Paediatrics, Queen Mary Hospital, The University of Hong Kong, Hong Kong. HEL cells were obtained from Dr Dong-Er Zhang, Department of
Pathology and Molecular Biology, Moores Cancer Center, University of California San Diego, USA. SET-2 cells were purchased from Deutsche Sammlung von Mikroorganismen und Zellkulturen GmbH (DMSZ) (Braunschweig, Germany). SET-2 was derived from ET at megakaryoblastic leukemic transformation. HEL was derived from AML M6. Both SET-2 and HEL cells carry JAK2 V617F mutation. MEG-01 and K-562 were derived from blastic transformation of patients with CML. Cell cultures were maintained in RPMI media 1640 (Invitrogen, Carlsbad, CA), supplemented with 10\% (20\% for SET-2) fetal bovine serum (Invitrogen, Carlsbad, CA), $50 \mathrm{U} / \mathrm{ml}$ penicillin, and $50 \mu \mathrm{g} / \mathrm{ml}$ streptomycin (Invitrogen, Carlsbad, CA) in a humidified atmosphere of $5 \% \mathrm{CO}_{2}$ at $37^{\circ} \mathrm{C}$.

\section{Methylation-specific polymerase chain reaction (MSP)}

DNA was extracted from bone marrow samples at diagnosis and from cell lines by standard method. MSP for aberrant gene promoter methylation was performed as previously described [13,14]. Treatment of DNA with bisulfite for conversion of unmethylated cytosine to uracil (but unaffecting methylated cytosine) was performed with a commercially available kit (EpiTect Bisulfite Kit, Qiagen, Germany). Primers used for the methylated MSP (MMSP) and unmethylated MSP (U-MSP) were shown in Table 2. DNA from normal bone marrow donors was used as negative control, while enzymatically methylated control DNA (CpGenome Universal Methylated DNA, Chemicon) was used as positive control in all the experiments. MSP was performed in a thermal cycler (9700, Applied Biosystems, Foster City, CA) with the following cycling conditions: $95^{\circ} \mathrm{C}$ for 5 minutes, specific cycles of $95^{\circ} \mathrm{C}$ for 30 seconds, specific annealing temperature for 30 seconds (Table 2), $72^{\circ} \mathrm{C}$ for 30 seconds, and a final extension of 10 minutes at $72^{\circ} \mathrm{C}$. The MSP mixture contained $50 \mathrm{ng}$ of bisulfite-treated DNA, $0.2 \mathrm{mM}$ dNTPs, $\mathrm{MgCl}_{2}$ (Table 2), 10 pmol of each primer, $1 \times$ PCR buffer, and 2.5 units of AmpliTaq Gold DNA Polymerase (Applied Biosciences, Foster City, CA) in a final volume of $25 \mu \mathrm{l}$. Ten microliters of PCR products were loaded onto $6 \%$ nondenaturing polyacrylamide gels, electrophoresed, and visualized under ultraviolet light after staining with ethidium bromide.

\section{5-aza-2'-deoxycytidine (5-AzadC) treatment}

HEL cells were homozygously methylated for $m i R-34 b / c$. Cells were seeded in six-well plates at a density of $1 \times 10^{6}$ cells $/ \mathrm{ml}$, and cultured with $1.5 \mu \mathrm{M}$ of 5 -AzadC for 7 days. Cells on day 0 and day 7 of treatment were harvested.

RNA isolation and stem-loop reverse transcriptionpolymerase chain reaction (RT-PCR)

Total RNA was isolated using mirVana ${ }^{\mathrm{TM}}$ miRNA Isolation Kit (Ambion, Austin, TX), according to the manufacturer's 
Table 1 Patient demographic data and status of microRNA methylation

\begin{tabular}{|c|c|c|c|c|c|c|c|c|c|}
\hline sex & age & Diagnosis & Symptoms at diagnosis & myeloid transformation & JAK2 V617F mutation & $\mathrm{miR}-34 \mathrm{~b} / \mathrm{c}$ & $\operatorname{miR}-34 a$ & miR-203 & miR-124-1 \\
\hline $\mathrm{F}$ & 78 & ET & Epigastric pain & No & yes & $u$ & $U$ & $M$ & $U$ \\
\hline $\mathrm{F}$ & 81 & ET & Epigastric pain & No & yes & $U$ & U & $U$ & U \\
\hline M & 32 & ET & erythromelalgia & No & yes & $U$ & U & U & U \\
\hline M & 81 & ET & N/A & No & yes & U & U & U & U \\
\hline M & 59 & ET & N/A & N/A (No record) & yes & M & U & U & U \\
\hline M & 76 & ET & Nil & No & yes & $U$ & M & U & U \\
\hline M & 53 & ET & $\mathrm{Nil}$ & MDS & yes & U & $U$ & U & U \\
\hline $\mathrm{F}$ & 89 & ET & $\mathrm{Nil}$ & N/A (No record) & yes & $U$ & U & $U$ & U \\
\hline $\mathrm{F}$ & 43 & ET & $\mathrm{Nil}$ & N/A (No record) & yes & M & U & M & U \\
\hline$F$ & 82 & ET & $\mathrm{Nil}$ & No & yes & $U$ & U & $U$ & U \\
\hline M & 78 & ET & $\mathrm{Nil}$ & No & yes & $U$ & U & U & U \\
\hline $\mathrm{F}$ & 79 & ET & $\mathrm{Nil}$ & No & yes & $U$ & U & U & U \\
\hline M & 84 & ET & $\mathrm{Nil}$ & AML & yes & U & U & $U$ & U \\
\hline $\mathrm{F}$ & 74 & ET & $\mathrm{Nil}$ & No & yes & M & U & M & U \\
\hline $\mathrm{F}$ & 56 & ET & $\mathrm{Nil}$ & No & yes & $U$ & U & $U$ & U \\
\hline M & 60 & ET & $\mathrm{Nil}$ & No & N/A & u & U & U & U \\
\hline M & 68 & ET & $\mathrm{Nil}$ & AML & yes & u & U & U & U \\
\hline M & 39 & ET & $\mathrm{Nil}$ & No & yes & $u$ & U & U & U \\
\hline$F$ & 79 & ET & Weight loss & No & yes & U & U & U & U \\
\hline$F$ & 60 & ET & erythromelalgia & No & no & $u$ & $u$ & $u$ & $u$ \\
\hline M & 63 & ET & Minor stroke (LUL numbness) & No & no & $U$ & U & U & U \\
\hline M & 47 & ET & erythromelalgia & No & no & $u$ & U & U & U \\
\hline F & 62 & ET & erythromelalgia, Headache & No & no & $U$ & U & $U$ & U \\
\hline $\mathrm{F}$ & 83 & ET & N/A & N/A (No record) & no & $U$ & U & M & U \\
\hline $\mathrm{F}$ & 32 & ET & Nil & N/A (No record) & no & $U$ & U & $U$ & U \\
\hline $\mathrm{F}$ & 42 & ET & Nil & No & no & M & U & U & U \\
\hline M & 85 & ET & $\mathrm{Nil}$ & No & no & $U$ & U & U & U \\
\hline M & 71 & ET & $\mathrm{Nil}$ & No & no & U & U & U & U \\
\hline$F$ & 28 & ET & $\mathrm{Nil}$ & No & no & u & U & U & U \\
\hline $\mathrm{F}$ & 87 & ET & $\mathrm{Nil}$ & No & no & U & U & U & U \\
\hline M & 48 & ET & $\mathrm{Nil}$ & No & no & U & U & U & U \\
\hline M & 48 & ET & Nil & No & no & U & U & U & U \\
\hline M & 41 & ET & epistaxis & No & $\mathrm{N} / \mathrm{A}$ & U & U & U & U \\
\hline M & 82 & $\mathrm{ET}$ & N/A & No & N/A & $U$ & U & U & $U$ \\
\hline$F$ & 41 & PMF & Easy bruising & N/A (No record) & yes & U & U & U & U \\
\hline M & 67 & PMF & Nil & No & yes & U & U & U & $U$ \\
\hline $\mathrm{F}$ & 82 & PMF & Nil & No & yes & $U$ & $U$ & U & U \\
\hline
\end{tabular}


Table 1 Patient demographic data and status of microRNA methylation (Continued)

\begin{tabular}{|c|c|c|c|c|c|c|c|c|c|}
\hline F & 42 & PV & Minor stroke (RUL paraesthesia) & No & yes & $U$ & $U$ & $U$ & $U$ \\
\hline M & 48 & PV & Gum bleeding & No & yes & $U$ & U & U & U \\
\hline $\mathrm{F}$ & 75 & PV & Nil & AML & yes & $U$ & U & U & U \\
\hline M & 78 & PV & Nil & No & yes & U & U & U & U \\
\hline M & 57 & PV & Visual blurring (BRAO) & No & yes & $U$ & U & U & $u$ \\
\hline M & 44 & PV & abdominal pain (splenic infarction) & No & no & U & U & U & U \\
\hline M & 71 & PV & Gum bleeding & MDS & N/A & $u$ & U & U & U \\
\hline $\mathrm{F}$ & 77 & PV & N/A & No & N/A & U & U & U & U \\
\hline
\end{tabular}

Abbreviations: ET: essential thrombocythemia; PV: polycythemia vera; PMF: primary myelofibrosis; CVA: cerebrovascular acccident; BRAO: branch retinal vein occlusion; LUL: left upper limb; RUL: right upper limb; AML: acute myeloid leukemia; MDS: myelodysplastic syndrome; N/A: not available; U: unmethylated; M: methylated 
Table 2 MSP primer sequences and reaction conditions

\begin{tabular}{|c|c|c|c|c|}
\hline Gene & Forward primer $\left(5^{\prime}-3^{\prime}\right)$ & Reverse primer $\left(5^{\prime}-3^{\prime}\right)$ & $\mathrm{MgCl}_{2} / \mathrm{Tm} /$ Cycles & Reference \\
\hline \multicolumn{5}{|l|}{$\operatorname{miR}-34 a$} \\
\hline M-MSP & GGGGATGAGGATTAGGATTTC & ACAAAACGCATAAAAACGACG & $1.5 \mathrm{mM} / 58^{\circ} \mathrm{C} / 35$ & [9] \\
\hline U-MSP & GGGGATGAGGATTAGGATTIT & CAAACAAAACACATAAAAACAACA & $1.5 \mathrm{mM} / 58^{\circ} \mathrm{C} / 35$ & \\
\hline \multicolumn{5}{|l|}{$\operatorname{miR}-34 b / c$} \\
\hline M-MSP & ATTCGTTTCGTTTCGCGTTCGTTC & CGACTACAACTCCCGAACGATCCG & $2.0 \mathrm{mM} / 58^{\circ} \mathrm{C} / 35$ & {$[34,35]$} \\
\hline U-MSP & TITTATTTGTTTGTTITGTGTTTGTITG & CAACTACAACTCCCAAACAATCC & $1.25 \mathrm{mM} / 56^{\circ} \mathrm{C} / 38$ & \\
\hline \multicolumn{5}{|l|}{ miR-124-1 } \\
\hline M-MSP & AAAGAGTTITGGAAGACGTC & AATAAAAAACGACGCGTATA & $1.5 \mathrm{mM} / 55^{\circ} \mathrm{C} / 35$ & [36] \\
\hline U-MSP & AATAAAGAGTTITTGGAAGATGTT & AAAAAAATAAAAAACAACACATATAC & $2.0 \mathrm{mM} / 55^{\circ} \mathrm{C} / 35$ & \\
\hline \multicolumn{5}{|l|}{ miR-203 } \\
\hline M-MSP & GAGTATITTGGTTAGACGAGAC & CCTITTATACGACGCAACCG & $1.5 \mathrm{mM} / 58^{\circ} \mathrm{C} / 35$ & {$[37]$} \\
\hline U-MSP & TाTGAGTATTITGGTTTAGATGAGAT & AACACCTTTTATACAACACAACCA & $1.5 \mathrm{mM} / 58^{\circ} \mathrm{C} / 35$ & \\
\hline
\end{tabular}

Abbreviations: Tm, annealing temperature; M-MSP, MSP for the methylated allele; U-MSP, MSP for the unmethylated allele

instructions. RT was performed using Taqman ${ }^{\circledR}$ MicroRNA RT Kit and Taqman ${ }^{\circledR}$ MicroRNA Assay Kit (Applied Biosciences, Foster City, CA), according to the manufacturer's instructions. Total RNA was reverse transcribed in $1 \mathrm{mM}$ dNTPs, 50 U MultiScribe ${ }^{\mathrm{TM}}$ Reverse Transcriptase, 1X RT Buffer, 3.8 U RNase Inhibitor, and 1X stem-loop RT primer at the following thermal cycling condition: $16^{\circ} \mathrm{C}$ for 30 minutes, $42^{\circ} \mathrm{C}$ for 30 minutes, and $85^{\circ} \mathrm{C}$ for $5 \mathrm{~min}$ utes. Quantitative real-time PCR was performed using 1.33 $\mu \mathrm{l}$ of 1:15 diluted RT product in $1 \mathrm{X}$ Taqman ${ }^{\circledR}$ Universal PCR Master Mix, and $1 \mathrm{X} \operatorname{Taqman}^{\circledR}$ Assay at $95^{\circ} \mathrm{C}$ for 10 minutes, followed by 40 cycles of $95^{\circ} \mathrm{C}$ for 15 seconds and $60^{\circ} \mathrm{C}$ for 1 minute. RNU48 was used as reference for data analysis using the $2^{-\Delta \Delta \mathrm{Ct}}$ method [15]. Conventional RT-PCR for primary $m i R-34 a$ was performed as previously described [9].

\section{Statistical analysis}

Correlation between combined miR methylation status (i.e. those with methylation of any of these four miRs) with categorical variables (gender, MPN subtype, occurrence of myeloid transformation, development of thrombosis [either at diagnosis or after diagnosis of MPN] and presence of JAK2 V617F mutation) and continuous variables (age, presenting $\mathrm{Hb}$, leukocyte and platelet counts) was computed by the Chi-square test (or Fisher Exact test) and Student's T-test. All p-values were two-sided.

\section{Results \\ MSP \\ Controls}

Direct sequencing of the M-MSP products from the methylated positive control confirmed the MSP specificity and complete bisulfite conversion, which methylated cytosine remained as cytosine upon sequencing (underlined) while unmethylated cytosine appeared as thymidine (Figure 1A). The positive and negative controls showed expected MSP results with normal DNA showing positive U-MSP but negative M-MSP amplification; and conversely, methylated control DNA showing negative U-MSP but positive M-MSP amplification. None of the 8 normal control marrows showed aberrant methylation of miR-34a, $-34 b / c,-124-1$ or -203 (Figure 1B).

\section{Cell lines}

MSP analysis of the four cell lines showed that $m i R-34 a$ was hemizygously methylated in MEG-01 and K-562 and completely unmethylated in HEL and SET-2. miR$34 b / c$ was completely methylated in HEL, hemizygously methylated in MEG-01 and completely unmethylated in K-562 and SET-2. miR-124-1 was completely unmethylated in all the four cell lines. miR-203 was completely unmethylated in K-562 and SET-2. However, there was neither U- or M-MSP signals of miR-203 in both HEL and MEG-01, suggesting a possibility of homozygous deletion (Table 3; Figure 1C).

\section{Primary samples}

In the 45 primary bone marrow samples, $m i R-34 a$ was methylated in one (2.2\%), $m i R-34 b / c$ in four $(8.9 \%)$, $m i R-$ 203 in four $(8.9 \%)$ of patients but none had methylation of miR-124-1 (Figure 2; Table 1). Moreover, two (4.4\%) had concomitant methylation of $m i R-34 b / c$ and -203 but none had concomitant methylation of $m i R-34 a$ and $-34 b / c$. Direct sequencing of the methylated MSP products confirmed methylation of miRs in the primary samples (Figure $2)$. With regards to the MPN subtype, miR-34a methylation occurred in a patient with ET (2.9\%), and miR-203 in four patients $(11.8 \%)$ with ET. On the other hand, $m i R$ $34 \mathrm{~b} / \mathrm{c}$ methylation occurred in three patients $(8.8 \%)$ with ET and one patient (12.5\%) with PV. Overall, seven patients $(15.6 \%)$ had methylation of at least one of the three miRs. $m i R$ methylation was not associated with age $(\mathrm{p}=0.651)$, gender $(\mathrm{p}=0.225)$, MPN subtype $(\mathrm{p}=0.484)$, presenting $\mathrm{Hb}(\mathrm{p}=0.874)$, presenting leukocyte count $(\mathrm{p}=0.969)$, presenting platelet count $(\mathrm{p}=0.328)$, myeloid 


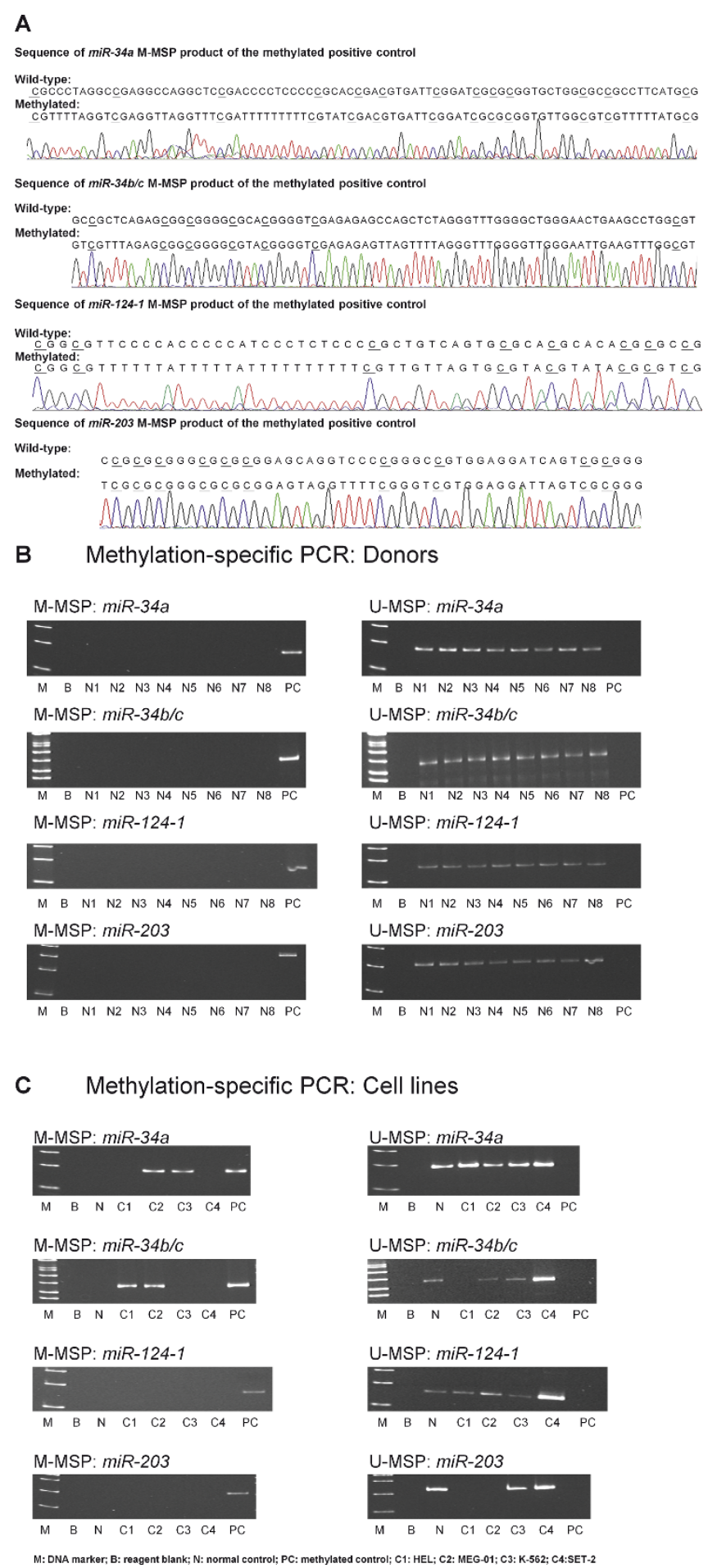

Figure 1 Methylation of $m i R-34 a, m i R-34 b / c, m i R-124-1$ and $m i R-203$. A) Sequence analysis of the M-MSP product from bisulfite-treated positive control DNA showed that the cytosine $[\mathrm{C}]$ residues of $\mathrm{CpG}$ dinucleotides were methylated and remained unchanged, whereas all the other $\mathrm{C}$ residues were unmethylated and were converted to thymidine [T], confirming complete bisulfite conversion and MSP specificity. B) M-/ U-MSP analysis showed that all the eight normal controls [N1-N8] were unmethylated. C) In the cell lines, MEG-01 and K-562 were hemizygously methylated for miR-34a; HEL was completely methylated, MEG-01 was hemizygously methylated for miR-34b/c; all the four cell lines were unmethylated for miR-124-1; K-562 and SET-2 were completely unmethylated for miR-203. 
Table 3 MSP of miRs in cell lines

\begin{tabular}{|c|c|c|c|c|}
\hline & miR-34a & $m i R-34 b / c$ & miR-124-1 & miR-203 \\
\hline Chromosomal location of miR & $1 \mathrm{p} 36$ & $11 q 23$ & $8 p 23$ & $14 q 32$ \\
\hline HEL & UU & MM & UU & $-/-$ \\
\hline MEG-01 & UM & UM & UU & $-/-$ \\
\hline K-562 & UM & UU & UU & UU \\
\hline SET-2 & UU & UU & UU & UU \\
\hline
\end{tabular}

UU: completely unmethylated; UM: hemizygously methylated; MM: homozygously methylated;

-/-: absence of both U- and M-MSP signals

transformation $(\mathrm{p}=0.99)$, thrombotic events $(\mathrm{p}=0.311)$ or JAK2 V617F mutation ( $\mathrm{p}=0.99)$.

\section{5-AzadC treatment of HEL cells}

Untreated HEL cells were homozygously methylated for $m i R-34 b / c$ (Chr. 11q23). After 5-AzadC hypomethylation treatment, $m i R-34 b / c$ U-MSP signal emerged, together with about 3 -fold increase in expression of both mature $m i R-34 b$ and $m i R-34 c$ on day 7 as analyzed by stem-loop RT-PCR (Figure 3). On the other hand, $m i R-34 a$ was unmethylated in HEL. By conventional RT-PCR of the primary transcript of $m i R-34 a$, pri-miR$34 a$ was not constitutively expressed, and treatment with 5-AzadC did not lead to expression of primary miR-34a (Additional file 1).

\section{Discussion}

Little information is available about the role of miRs in MPNs. Based on a literature search on the PubMed using keywords of "microRNA, methylation and myeloproliferative", no publication could be found. Therefore, this is likely the first report on methylation of miRs in MPN. In this study, we examined the methylation of $m i R-34 a,-34 b / c$, $-124-1$ and -203 for a range of MPNs. In an attempt to identify miRs specifically involved in erythropoiesis, miR expression from in vitro expansion of erythroid cells derived from peripheral blood mononuclear cells were compared with controls, which showed $m i R-451$ upregulation was specific to erythropoiesis [16]. On the other hand, during in vitro differentiation of megakaryocytes derived from CD34+ hematopoietic progenitors, downregulation of miR-10a, $-10 b,-17,-20,-106$ and -126 was observed [17]. Moreover, when comparing the miR expression profiling of megakaryoblastic cell line with in vitro differentiated megakaryocytes, upregulation of miR-99a, -101, -126, and -135 was also found [17]. Therefore, the upregulation and downregulation of these specific miRs were associated with megakaryocytic and erythropoietic differentiation.

Despite that multiple TSGs were shown to be silenced by hypermethylation in AML [4,14,18-22], methylation of tumor suppressor genes was less frequently reported in MPN. Only recently, there were a few reports of methylation of the negative regulators of the JAK-STAT signaling pathway, SOCS1, SOCS2 and SOCS3, in Ph-ve MPN regardless of the JAK2 V617F mutation status [23-26].
Furthermore, based on previous work by us and others, CDK6 has been shown to be the target of multiple miRs including $m i R-34 a,-34 b / c$ and $-124-1$ [27,28]. Moreover, $C R E B$ is the target of $m i R-34 b$ and -203 [10,29]. Finally, $A B L$ is an additional target of $m i R-203$ [12]. Consequently, epigenetic silencing of tumor suppressor $m i R-34 a$, $m i R$ $34 b / c, m i R-124-1$ and $m i R-203$ will confer proliferative advantage to the tumor cells [27-29]. In contrast to a previous report which showed $m i R-203$ was methylated in $\mathrm{Ph}$ +ve but not Ph-ve MPN or leukemia, using MSP primers in the similar region [12], we demonstrated that $m i R-203$ was hypermethylated in primary MPN samples, which was further verified by direct sequencing of the methylated MSP products. Therefore, it would appear that miR-203 methylation is involved in a wider spectrum of MPNs or leukemias, regardless of their $\mathrm{Ph}$ chromosome status. Finally, while two patients had concomitant methylation of $m i R-203$ and $-34 b / c$, none had concomitant methylation of $m i R-34 a$ and $-34 b / c$, both transcriptional targets of $\mathrm{p} 53$, and hence avoiding duplication of tumor suppressor gene inactivation of the same pathway.

In HEL and MEG-01 cells, both U- and M-MSP signals of $m i R-203$ were absent, which might be due to the following possibilities: (1) sample DNA degradation, (2) inappropriate PCR condition, or (3) homozygous deletion of the region. Since simultaneous U-MSP analysis of the same DNA sample for $m i R-34 a, m i R-34 b / c$, and $m i R-124-$ 1 promoter successfully generated the U-MSP signals, hence the absence of MSP signals for $m i R-203$ in HEL and MEG-01 cells could not be explained by a poor DNA quality. Moreover, as miR-203 U-MSP was successful in all the other samples including cell lines, normal controls, patient samples and methylated positive control, inappropriate MSP conditions appears unlikely. Therefore, the absence of both M- and U-MSP signals in HEL and MEG01 cells might be caused by deletions of the region. However, karyotypic data of HEL and MEG-01 cells did not reveal homozygous deletion of 14q32, and hence whether absence of MSP amplification of miR-203 might be due to microdeletion of this region requires further study [30]. Furthermore, hypomethylation treatment of the HEL cells, which was homozygously methylated for the $m i R-34 b / c$, a microRNA cluster localized to $11 \mathrm{q} 23$, showed significant re-expression of mature $m i R-34 b$ and $m i R-34 c$. This 


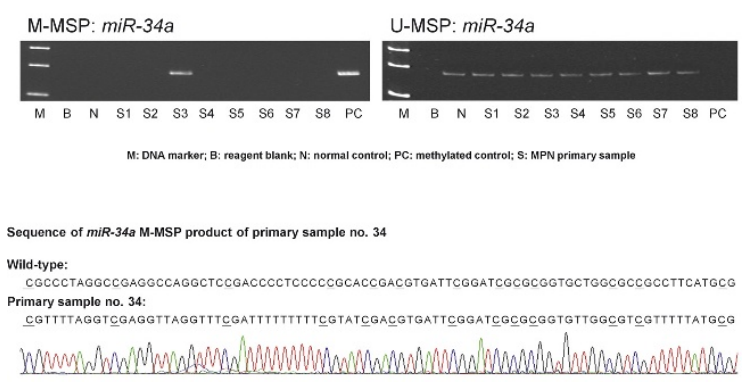

\section{B Methylation of $m i R-34 b / c$ in MPN primary samples}

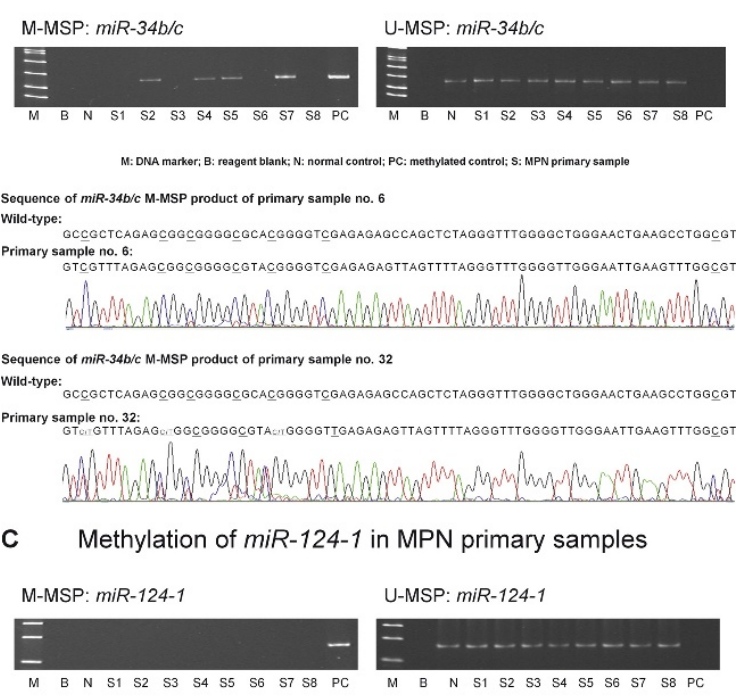

M: DNA marker; B: reagent blank; N: normal control; PC: methylated control; s: MPN primary sample

\section{Methylation of $m i R-203$ in MPN primary samples}

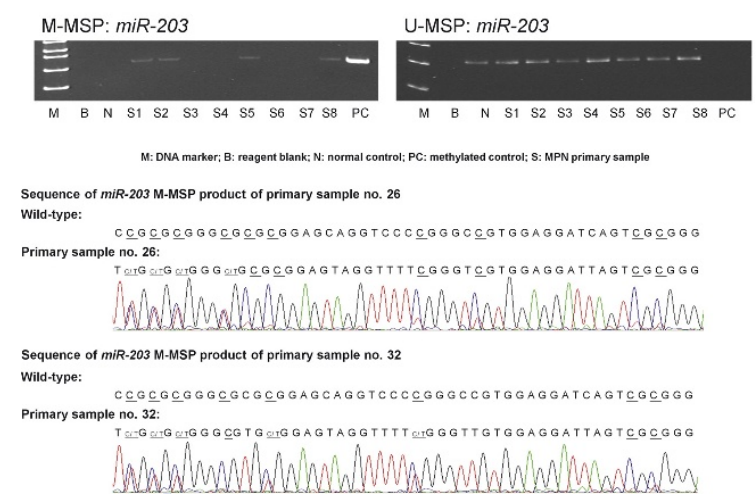

Figure 2 Methylation of $m i R-34 a, m i R-34 b / c, m i R-124-1$ and $m i R-203$ in primary samples. For each of these miRs, M-/U-MSP and sequencing of the M-MSP product from representative bisulfite-treated primary samples were shown. In the sequence analysis of the M-MSP product, cytosine $[\mathrm{C}]$ residues of $\mathrm{CpG}$ dinucleotides were methylated and remained unchanged, partially methylated $\mathrm{C}$ residues were denoted as $[C / T$, unmethylated $\mathrm{C}$ residues were converted into [] , whereas all the non- $\mathrm{CpG} C$ residues were unmethylated and were converted to thymidine [] , confirming complete bisulfite conversion and MSP specificity. 


\section{5-AzadC treatment of HEL cells}

A $m i R-34 b / c$

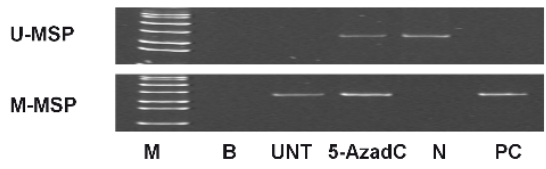

M: marker; B: reagent blank; N: normal donor; PC: methylated positive control UNT: untreated control; 5-AzadC: culture in 1.5 UM 5-AzadC

B

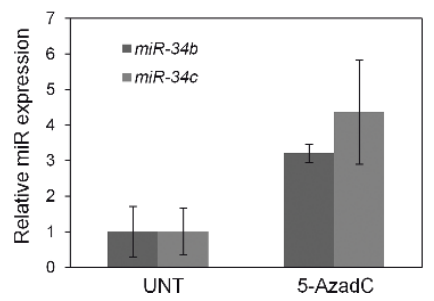

Figure 3 Effect of 5-aza-2'-deoxycytidine (5-AzadC) treatment on HEL cells. A) M-/U-MSP analysis of miR-34b/c promoter methylation status showed that 5-AzadC treatment led to progressive demethylation of miR-34b/c promoter in HEL cells. B) Stem-loop qRT-PCR analysis of mature miR-34b and miR-34c expression in HEL cells seven days after treatments. Error bar represents standard deviation.

finding is consistent with that both $m i R-34 b$ and $m i R-34 c$ are under the promoter regulation of the same $C p G$ island. By contrast, $m i R-34 a$, another member of the miR34 family localized to $1 \mathrm{p} 36$, was not constitutively expressed. Moreover, hypomethylating treatment did not lead to expression of primary miR-34a, suggesting additional mechanism, possibly histone modification, in the regulation of $m i R-34 a$ expression [9]. Furthermore, in addition to showing miR silencing in cell line, it is important to show the correlation of miR methylation and miR expression in the primary sample. In this connection, we shall collect both DNA and RNA from diagnostic bone marrow samples in the future.

In order to identify miRs that are methylated specifically at the time of transformation to AML or MDS, and hence implicated for pathogenesis of myeloid transformation, ideally one should analyze the paired marrow samples at both diagnosis and leukemic/myelodysplastic transformation. This is exemplified by our recent publication in the study of epigenetic inactivation of miR-34b/c methylation in myeloma, in which we showed that while $m i R-34 b / c$ is not methylated at diagnosis, it is frequently methylated at the time of relapse or disease progression. This is as evidenced by the significantly more frequent methylation of $m i R-34 b / c$ of myeloma samples at relapse in patients with both diagnostic and relapse marrow samples[31].

Finally, unlike the association of TSG with clinical parameters, such as the association of $C D K N 2 B$ and
WIF1 methylation with high presenting leukocyte count in acute promyelocytic leukemia [32,33], methylation of these miRs did not correlate with demographic, presenting blood counts, JAK2 V617F mutation or complications including thrombosis and myeloid transformations.

\section{Conclusion}

This is the first report of miR hypermethylation in MPNs. miR-203 hypermethylation is not specific to $\mathrm{Ph}$ +ve leukemias but also present in Ph-ve MPNs. miR$34 b / c$ methylation was associated with reversible miR silencing. There was no correlation of miR methylation with clinical demographic data or outcome.

\section{Additional material}

Additional file 1: Effect of 5-aza-2'-deoxycytidine (5-AzadC)

treatment on HEL cells. 5-AzadC treatment of HEL cells.

\section{Author details}

'Department of Medicine, Queen Mary Hospital, The University of Hong Kong, Hong Kong. ${ }^{2}$ Department of Pathology, Queen Mary Hospital, The University of Hong Kong, Hong Kong. ${ }^{3}$ Department of Human and Animal Cell Cultures, DSMZ - German Collection of Microorganisms and Cell Cultures, Inhoffenstr. 7B 38126 Braunschweig, Germany. ${ }^{4}$ Department of Pathology, Queen Elizabeth Hospital, Hong Kong.

\section{Authors' contributions}

All authors read and approved the final manuscript. CSC is responsible for design of study, interpretation of data and writing manuscript. TSW is responsible for provision of study material. KYW and TKF are responsible for conduction of experiment. HGD is responsible for provision of cell lines. KFW is responsible for provision of patients' material.

\section{Competing interests}

The authors declare that they have no competing interests.

Received: 7 April 2011 Accepted: 14 November 2011

Published: 14 November 2011

\section{References}

1. Tefferi A, Thiele J, Orazi A, Kvasnicka HM, Barbui T, Hanson CA, Barosi G, Verstovsek S, Birgegard G, Mesa R, et al: Proposals and rationale for revision of the World Health Organization diagnostic criteria for polycythemia vera, essential thrombocythemia, and primary myelofibrosis: recommendations from an ad hoc international expert panel. Blood 2007, 110:1092-1097.

2. Chim CS, Kwong YL, Lie AKW, Ma SK, Chan CC, Wong LG, San Kho BC, Lee HK, Sim JPY, Chan CH, et al: Long-term Outcome of 231 Patients With Essential Thrombocythemia: Prognostic Factors for Thrombosis, Bleeding, Myelofibrosis, and Leukemia. Arch Intern Med 2005, 165:2651-2658.

3. Chim CS, Kwong YL, Chan PT, Raymond L: Polycythemia vera in Chinese patients: Thirty-six years of experience. American Journal of Hematology 1997, 56:59-62.

4. Chim CS, Liang R, Kwong YL: Hypermethylation of gene promoters in hematological neoplasia. Hematol Oncol 2002, 20:167-176.

5. Chen CZ: MicroRNAs as Oncogenes and Tumor Suppressors. N Engl J Med 2005, 353:1768-1771.

6. Calin GA, Croce CM: MicroRNA signatures in human cancers. Nat Rev Cancer 2006, 6:857-866.

7. Esquela-Kerscher A, Slack FJ: Oncomirs - microRNAs with a role in cancer. Nat Rev Cancer 2006, 6:259-269. 
8. Lodygin D, Tarasov V, Epanchintsev A, Berking C, Knyazeva T, Korner H, Knyazev P, Diebold J, Hermeking H: Inactivation of miR-34a by aberrant CpG methylation in multiple types of cancer. Cell Cycle 2008, 7:2591-2600.

9. Chim CS, Wong KY, Qi Y, Loong F, Lam WL, Wong LG, Jin DY, Costello JF, Liang R: Epigenetic inactivation of the miR-34a in hematological malignancies. Carcinogenesis 2010, 31:745-750.

10. Pigazzi M, Manara E, Baron E, Basso G: miR-34b Targets Cyclic AMPResponsive Element Binding Protein in Acute Myeloid Leukemia. Cancer Res 2009, 69:2471-2478.

11. Agirre X, Vilas-Zornoza A, Jimenez-Velasco A, Martin-Subero Jl, Cordeu L, Garate L, San Jose-Eneriz E, Abizanda G, Rodriguez-Otero P, Fortes P, et al: Epigenetic Silencing of the Tumor Suppressor MicroRNA Hsa-miR-124a Regulates CDK6 Expression and Confers a Poor Prognosis in Acute Lymphoblastic Leukemia. Cancer Res 2009, 69:4443-4453.

12. Bueno MJ, Perez de Castro I, Gomez de Cedron M, Santos J, Calin GA, Cigudosa JC, Croce CM, Fernandez-Piqueras J, Malumbres M: Genetic and Epigenetic Silencing of MicroRNA-203 Enhances ABL1 and BCR-ABL1 Oncogene Expression. Cancer Cell 2008, 13:496-506.

13. Chim CS, Fung TK, Cheung WC, Liang R, Kwong YL: SOCS1 and SHP1 hypermethylation in multiple myeloma: implications for epigenetic activation of the Jak/STAT pathway. Blood 2004, 103:4630-4635.

14. Chim CS, Liang R, Tam CYY, Kwong YL: Methylation of p15 and p16 Genes in Acute Promyelocytic Leukemia: Potential Diagnostic and Prognostic Significance. J Clin Oncol 2001, 19:2033-2040.

15. Livak KJ, Schmittgen TD: Analysis of Relative Gene Expression Data Using Real-Time Quantitative PCR and the 2-[Delta][Delta]CT Method. Methods 2001, 25:402-408.

16. Bruchova H, Yoon D, Agarwal AM, Mendell J, Prchal JT: Regulated expression of microRNAs in normal and polycythemia vera erythropoiesis. Experimental Hematology 2007, 35:1657-1667.

17. Garzon R, Pichiorri F, Palumbo T, Iuliano R, Cimmino A, Ageilan R, Volinia S, Bhatt $D$, Alder $H$, Marcucci $G$, et al: MicroRNA fingerprints during human megakaryocytopoiesis. Proceedings of the National Academy of Sciences of the United States of America 2006, 103:5078-5083.

18. Chim CS, Tam CYY, Liang R, Kwong YL: Methylation of p15 and p16 genes in adult acute leukemia. Cancer 2001, 91:2222-2229.

19. Chim CS, Wong ASY, Kwong YL: Epigenetic inactivation of the CIP/KIP cell-cycle control pathway in acute leukemias. American Journal of Hematology 2005, 80:282-287.

20. Chim CS, Wong SY, Pang A, Chu P, Lau JS, Wong KF, Kwong YL: Aberrant promoter methylation of the retinoic acid receptor alpha gene in acute promyelocytic leukemia. Leukemia 2005, 19:2241-2246.

21. Chim CS, Wong ASY, Kwong YL: Epigenetic dysregulation of the Jak/STAT pathway by frequent aberrant methylation of SHP1 but not SOCS1 in acute leukaemias. Annals of Hematology 2004, 83:527-532.

22. Chim CS, Wong SY, Kwong YL: Aberrant gene promoter methylation in acute promyelocytic leukaemia: profile and prognostic significance. $\mathrm{Br} J$ Haematol 2003, 122:571-578.

23. Capello D, Deambrogi C, Rossi D, Lischetti T, Piranda D, Cerri M, Spina V, Rasi S, Gaidano G, Lunghi M: Epigenetic inactivation of suppressors of cytokine signalling in Philadelphia-negative chronic myeloproliferative disorders. British Journal of Haematology 2008, 141:504-511.

24. Quentmeier H, Geffers R, Jost E, MacLeod RAF, Nagel S, Rohrs S, Romani J, Scherr M, Zaborski M, Drexler HG: SOCS2: inhibitor of JAK2V617Fmediated signal transduction. Leukemia 2008, 22:2169-2175.

25. Fourouclas N, Li J, Gilby DC, Campbell PJ, Beer PA, Boyd EM, Goodeve AC, Bareford D, Harrison CN, Reilly JT, et al: Methylation of the suppressor of cytokine signaling 3 gene (SOCS3) in myeloproliferative disorders. Haematologica 2008, 93:1635-1644.

26. Chim CS, Fung TK, Liang R: Methylation of cyclin-dependent kinase inhibitors, XAF1, JUNB, CDH13 and soluble Wnt inhibitors in essential thrombocythaemia. Journal of Clinical Pathology 2010, 63:518-521.

27. Wong KY, So CC, Loong F, Chung LP, Lam WWL, Liang R, Li GKH, Jin D-Y, Chim CS: Epigenetic Inactivation of the miR-124-1 in Haematological Malignancies. PLoS One 2011, 6:e19027.

28. Wong KY, Yu L, Chim CS: DNA methylation of tumor suppressor miRNA genes: a lesson from the miR-34 family. Epigenomics 2011, 3:83-92.

29. Wong KY, Liang R, So CC, Jin DY, Costello JF, Chim CS: Epigenetic silencing of MIR203 in multiple myeloma. British Journal of Haematology 2011, 154:569-578.
30. Drexler HG: Guide to Leukemia-Lymphoma Cell Lines. 2 edition. Braunschweig; 2010.

31. Wong KY, Yim RLH, So CC, Jin D-Y, Liang R, Chim CS: Epigenetic inactivation of the MIR34B/C in multiple myeloma. Blood 2011, 118:5901-5904.

32. Chim CS, Chan WWL, Pang A, Kwong YL: Preferential methylation of Wnt inhibitory factor-1 in acute promyelocytic leukemia: an independent poor prognostic factor. Leukemia 2006, 20:907-909.

33. Chim CS, Kwong YL: Adverse prognostic impact of CDKN2B hypermethylation in acute promyelocytic leukemia. Leukemia \& Lymphoma 2006, 47:815-825.

34. Lujambio A, Calin GA, Villanueva A, Ropero S, Sanchez-Cespedes M, Blanco D, Montuenga LM, Rossi S, Nicoloso MS, Faller WJ, et al: A microRNA DNA methylation signature for human cancer metastasis. PNAS 2008, 0803055105.

35. Toyota M, Suzuki H, Sasaki Y, Maruyama R, Imai K, Shinomura Y, Tokino T: Epigenetic Silencing of MicroRNA-34b/c and B-Cell Translocation Gene 4 Is Associated with CpG Island Methylation in Colorectal Cancer. Cancer Res 2008, 68:4123-4132.

36. Lujambio A, Ropero S, Ballestar E, Fraga MF, Cerrato C, Setien F, Casado S, Suarez-Gauthier A, Sanchez-Cespedes M, Gitt A, et al: Genetic Unmasking of an Epigenetically Silenced microRNA in Human Cancer Cells. Cancer Res 2007, 67:1424-1429.

37. Chim CS, Wong KY, Leung CY, Chung LP, Hui PK, Chan SY, Yu L: Epigenetic inactivation of the hsa-miR-203 in haematological malignancies. Journal of Cellular and Molecular Medicine 2011, 15:2760-2767.

doi:10.1186/1479-5876-9-197

Cite this article as: Chim et al:: Methylation of $m i R-34 a, m i R-34 b / c, m i R-$ 124-1 and miR-203 in Ph-negative myeloproliferative neoplasms. Journal of Translational Medicine 2011 9:197.

\section{Submit your next manuscript to BioMed Central and take full advantage of:}

- Convenient online submission

- Thorough peer review

- No space constraints or color figure charges

- Immediate publication on acceptance

- Inclusion in PubMed, CAS, Scopus and Google Scholar

- Research which is freely available for redistribution

Submit your manuscript at www.biomedcentral.com/submit
C) Biomed Central 